\title{
Pseudomyxoma peritonei
}

\begin{abstract}
Authors:
Binit Sureka

Mahesh K. Mittal ${ }^{1}$

Aliza Mittal $^{2}$

Mukul Sinha ${ }^{1}$

Brij B. Thukral

\section{Affiliations:}

${ }^{1}$ Department of

Radiodiagnosis and Imaging,

Vardhman Mahavir Medical

College and Safdarjung

Hospital, India

${ }^{2}$ Department of Paediatrics, Vardhman Mahavir Medical College and Safdarjung Hospital, India
\end{abstract}

\section{Correspondence to:}

Binit Sureka

Email:

binitsurekapgi@gmail.com

\section{Postal address:}

VMMC \& Safdarjung

Hospital, Resident Doctors

Hostel, Room 57, Second

Floor, New Delhi 110029,

India

\section{Dates:}

Received: 12 July 2013

Accepted: 01 Jan. 2014

Published: 23 Apr. 2014

How to cite this article:

Sureka B, Mittal MK, Mitta

A, Sinha M, Thukral BB.

Pseudomyxoma peritonei.

S Afr J Rad. 2014;18(1); Art.

\#585, 3 pages. http://dx.doi.

org/10.4102/sajr.v18i1.585

\section{Copyright:}

(C) 2014. The Authors.

Licensee: AOSIS

OpenJournals. This work

is licensed under the

Creative Commons

Attribution License.

\section{Read online:}

Pseudomyxoma peritonei is a rare complication of mucinous tumours of appendiceal or ovarian origin. Other associations are malignancies of the colon, urachus and biliary tree. Large amounts of extracellular and peritoneal mucin result in distortion and loss of function of visceral organs. Currently, radiology plays a critical role in diagnosing this rare entity, in follow-up and in predicting the outcome of cytoreductive surgeries.

\section{Discussion}

Pseudomyxoma peritonei (PMP), also known as 'jelly belly', 'gelatinous ascites' or 'false mucinous tumour of the peritoneum', is a rare complication with an estimated incidence of one to two cases per million per year. ${ }^{1}$ It occurs due to spillage of mucin from a ruptured mucinous tumour, leading to foreign body peritonitis. The most common cause is spread from a mucinous tumour of the appendix (see Figure 1 ). ${ }^{2}$ There is controversy over whether in these cases the ovary is the primary site or the appendix is the primary site and the ovarian lesion is metastatic (see Figure 2). ${ }^{3}$ Recently, mucin-2 protein (MUC 2) over-expression has been suggested as a molecular marker for PMP of intestinal origin. ${ }^{4}$ Other rare sources of PMP include malignancy of the colon (see Figures 3 and 4), stomach, uterus, pancreas, gallbladder, common bile duct and urachus (see Figure 5). Pseudomyxoma retroperitonei, also known as pseudomyxoma extraperitonei, is mucinous collection in the retroperitoneum, usually due to retroperitoneal rupture of a primary mucinous appendiceal tumour in a retrocaecal appendix.

The term pseudomyxoma peritonei was coined by Werth ${ }^{5}$ in 1884 . Ronnet et al. ${ }^{6}$ classified three pathological types of pseudomyxoma peritonei, namely (1) low-grade disseminated peritoneal adenomucinosis (DPAM), (2) high-grade peritoneal mucinous carcinomatosis (PMCA) and (3) peritoneal mucinous carcinomatosis with intermediate-grade or discordant features (PMCA-I/D). Patients with low-grade DPAM had significantly higher 5-year and 10-year survival rates compared to patients with PMCA and PMCA-I/D.

The basic pathophysiology in PMP is leakage of mucus containing epithelial cells into the peritoneal cavity from a ruptured mucinous tumor. ${ }^{7}$ The epithelial cells within the peritoneal cavity continue to proliferate, producing large quantities of mucus. The distinctive feature of PMP is its characteristic 'reorganisation' within the peritoneal cavity due to lack of adhesion molecules by the tumour cells. The open lymphatic lacunae on the under surface of the right hemidiaphragm and the lymphoid aggregate in the omentum absorb fluid, leading to bulky accumulations of concentrated mucus. From a radiological perspective, the concentrated tumour masses result in 'scalloping' of the liver surface and 'omental caking'.?

On imaging, plain films of the abdomen may reveal annular or semicircular calcific plaques, ascites and poorly defined soft-tissue masses. Calcification may also occur following chemotherapy. Ultrasound shows ascites with echogenic particles, displacement of small bowel loops medially and scalloping of surfaces of the liver and spleen. Characteristically, the echogenic particles in PMP do not move, unlike ascites associated with haemorrhage or pus in the peritoneum. CT shows low attenuation voluminous ascites, scalloping of visceral surfaces - particularly of the liver and spleen - and sometimes scattered (curvilinear or punctate) calcifications. Medial displacement of the tip of the right lobe of the liver due to focal collection of mucin in the right subhepatic space, known as Hellmer's sign, may be seen. ${ }^{8}$

Treatment involves surgical debulking, followed by infusion of intraperitoneal chemotherapy. Imaging also plays an important role in predicting the response to treatment. According to Jacquet, Jelinek, Chang et al., ${ }^{9}$ predictors of incomplete cytoreduction are segmental obstruction of the small bowel and tumour masses greater than $5 \mathrm{~cm}$ in width on the small bowel and its mesentery (exclusive of the distal ileum). Delayed enhancement of fluid on gadolinium-enhanced MRI suggests a favourable response to cytoreductive surgery. ${ }^{10}$ 

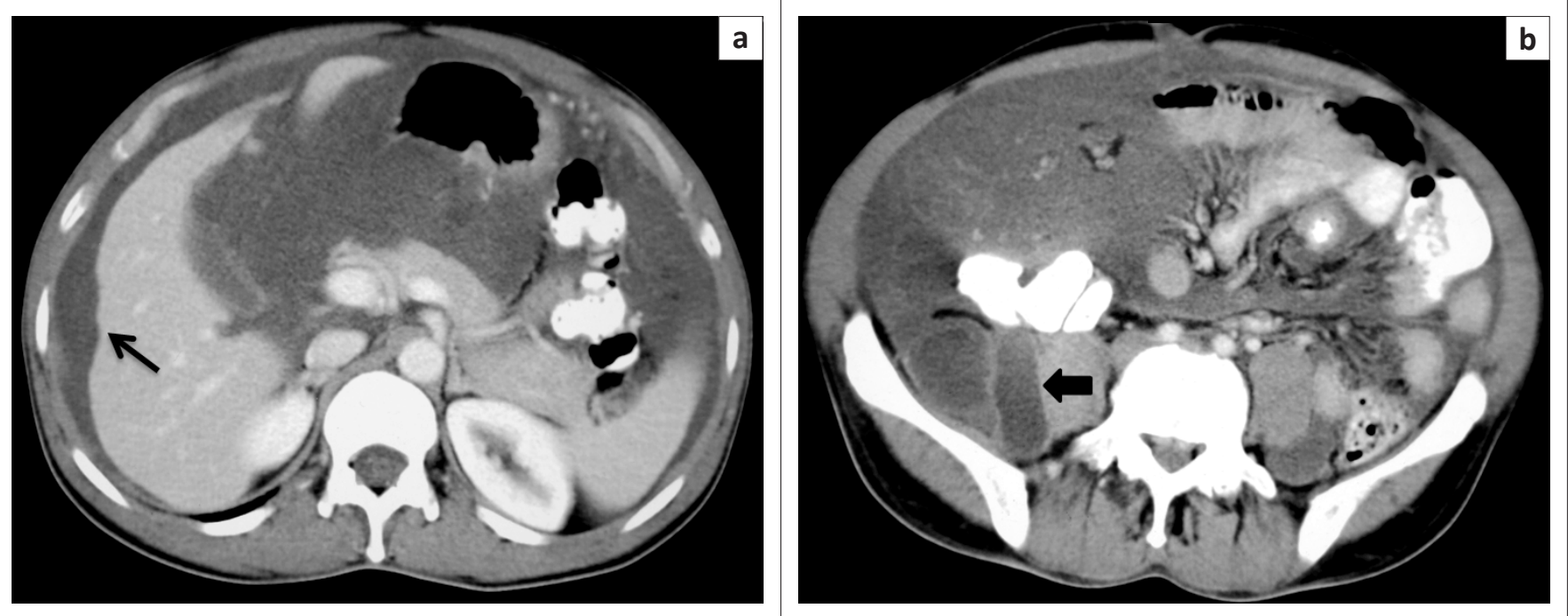

FIGURE 1: Pseudomyxoma peritonei in a 34-year-old male with abdominal distension and pain due to mucinous cystadenoma of the appendix. Intravenous and oral contrast-enhanced CT scans showing (a) low-density ascites causing scalloping of the liver surface (arrow) and (b) distended appendix (arrowhead) in right iliac fossa.
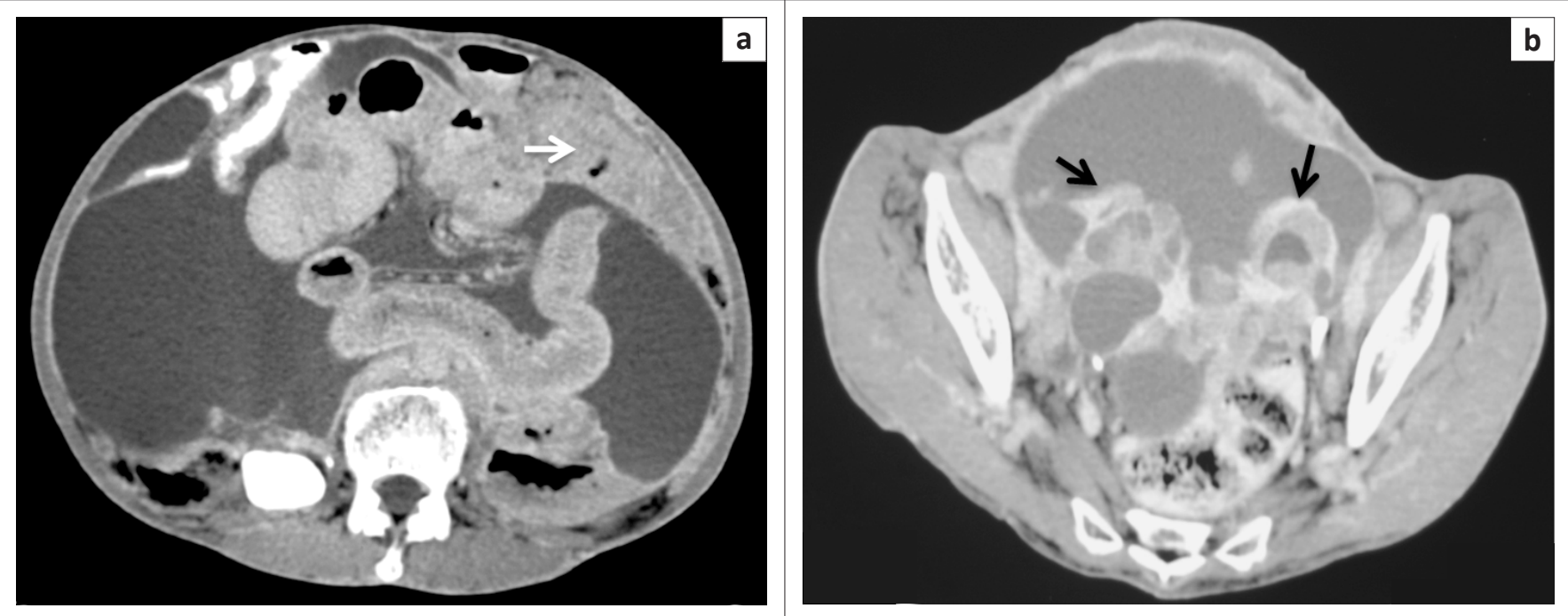

FIGURE 2: Pseudomyxoma peritonei in a 37-year-old female due to mucinous adenocarcinoma of the ovaries. Intravenous and oral contrast-enhanced CT scans showing (a) low-density ascites causing scalloping of bowel surface and omental caking (arrow) and (b) bilateral complex cystic ovarian masses (black arrows).

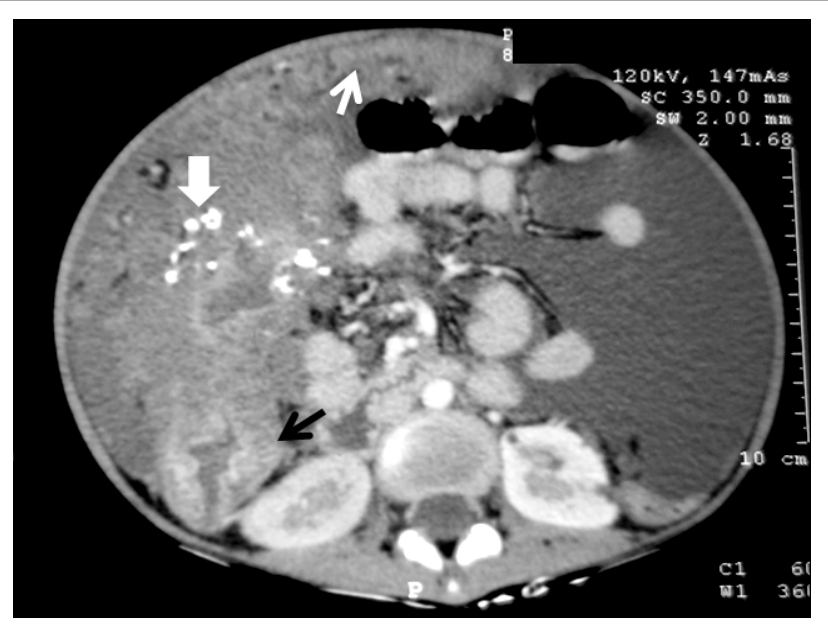

FIGURE 3: Histologically confirmed pseudomyxoma peritonei in a 12-year-old child due to mucinous adenocarcinoma of the colon. Contrast-enhanced CT scans showing asymmetric thickening of the ascending colon (black arrow) with coarse calcifications in the mesentry (arrowhead) and omental thickening (white arrow).

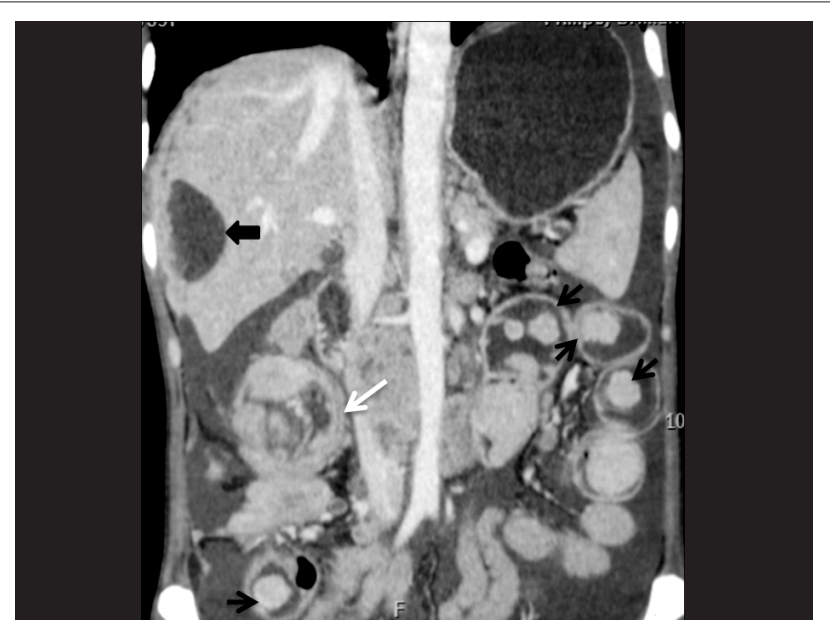

FIGURE 4: Pseudomyxoma peritonei in a 55-year-old male due to intestinal polyposis and mucinous carcinomatous transformation. Coronal reconstructed CT scan image showing multiple intestinal polyps (black arrows), leading to ileocolic intussusception (white arrow) and low-density ascites causing scalloping of the liver surface (arrowhead). 


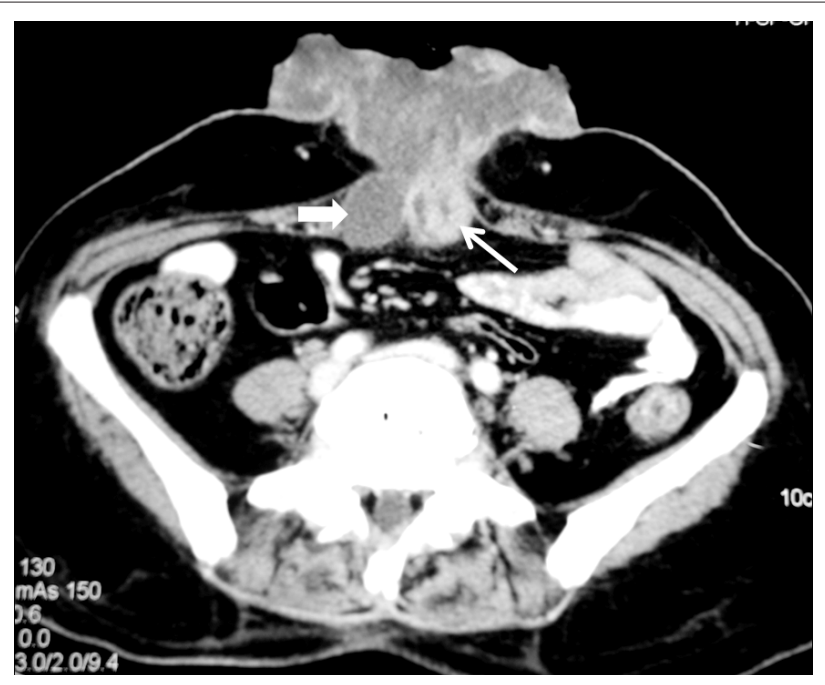

FIGURE 5: Histologically confirmed pseudomyxoma peritonei in a 65-year-old male with mucinous urachal adenocarcinoma. Axial contrast-enhanced CT scan showing urachal malignancy (white arrow) involving and extending up to the umbilicus with focal localised adjacent mucinous collection (arrowhead).

Differential diagnoses of PMP include peritoneal carcinomatosis, lymphomatosis, sarcomatosis, infectious peritonitis, inflammatory pseudotumour, gliomatosis peritonei, peritoneal hydatidosis and peritoneal melanosis.

\section{Acknowledgements}

\section{Authors' contributions}

B.S. (Vardhman Mahavir Medical College and Safdarjung Hospital) was responsible for concept design, literature search and manuscript preparation, M.K.M. (Vardhman Mahavir Medical College and Safdarjung Hospital) for manuscript review and definition of intellectual content, and A.M. (Vardhman Mahavir Medical College and Safdarjung
Hospital) for literature search, manuscript editing and the clinical study. M.S. (Vardhman Mahavir Medical College and Safdarjung Hospital) was involved in manuscript editing and in the clinical study, whilst B.B.T. (Vardhman Mahavir Medical College and Safdarjung Hospital) was the guarantor and was involved in manuscript editing.

\section{Competing interests}

The authors declare that they have no financial or personal relationship(s) that may have inappropriately influenced them in writing this article.

\section{References}

1. Smeenk RM, Van Velthuysen ML, Verwaal VJ, Zoetmulder FA. Appendiceal neoplasms and pseudomyxoma peritonei: A population based study. Eur J Surg Oncol. 2008;34:196-201. http://dx.doi.org/10.1016/j.ejso.2007.04.002

2. Takeuchi M, Matsuzaki K, Yoshida S, et al. Imaging findings of urachal mucinous cystadenocarcinoma associated with pseudomyxoma peritonei. ActaRadiol. 2004;45:348-350. http://dx.doi.org/10.1080/02841850410004959

3. Misdraji J. Appendiceal mucinous neoplasms: Controversial issues. Arch Pathol Lab Med. 2010;134:864-870.

4. Ferreira CR, Carvalho JP, Soares FA, et al. Mucinous ovarian tumors associated with pseudomyxoma peritonei of adenomucinosis type: Immunohistochemical evidence that they are secondary tumors. Int J Gynecol Cancer. 2008;18:59-65. http://dx.doi.org/10.1111/j.1525-1438.2007.00988.x

5. Werth R. Klinische and Anastomische Untersuchungen Zur Lehre von der Bauchgeswullsten und der laparotomy. Arch Gynecol Obstet. 1884;4:100-118.

6. Ronnett BM, Yan H, Kurman RJ, et al. Patients with pseudomyxoma peritonei associated with disseminated peritoneal adenomucosis have a significantly more favourable prognosis than patients with peritoneal mucinous carcinomatosis. Cancer. 2001 Jul; $92(1): 85-91$. http://dx.doi.org/10.1002/1097-
0142(20010701)92:1<85::AID-CNCR1295>3.0.CO;2-R

7. Bevan KE, Mohamed F, Moran BJ. Pseudomyxoma peritonei. World J Gastrointest Oncol. 2010;2:44-50. http://dx.doi.org/10.4251/wjgo.v2.i1.44

8. Dähnert W. Gastrointestinal disorders. In: Dähnert W, editor. Radiology review manual. 7th ed. Philadelphia, PA: Lippincott Williams \& Wilkins, 2011; p. 836

9. Jacquet $P$, Jelinek JS, Chang D, et al. Abdominal computed tomographic scan in the selection of patients with mucinous peritoneal carcinomatosis for cytoreductive surgery. J Am Coll Surg. 1995;181:530-538.

10. Low RN, Barone RM, Gurney JM, et al. Mucinous appendiceal neoplasms: Preoperative MR staging and classification compared with surgical and Preoperative MR staging and classification compared with surgical and
histopathologic findings. Am J Roentgenol. 2008;190:656-665. http://dx.doi. org/10.2214/AJR.07.2018 